University of Warwick institutional repository: http://go.warwick.ac.uk/wrap This paper is made available online in accordance with publisher policies. Please scroll down to view the document itself. Please refer to the repository record for this item and our policy information available from the repository home page for further information.

To see the final version of this paper please visit the publisher's website. Access to the published version may require a subscription.

Author(s): Michael Brennan

Article Title: Towards a Sociology of (Public) Mourning?

Year of publication: 2001

Link to published version:

http://dx.doi.org/10.1017/S003803850100013X

Publisher statement: None 
REVIEW ESSAY

\title{
Towards a Sociology of (Public) Mourning?
}

\author{
Michael Brennan \\ Department of Sociology \\ University of Warwick
}
Anthony Elliott, The Mourning of John Lennon, Berkeley: University of California Press, 1999, \$45.00 hardback ( $\$ 17.95$ paperback), xi+219 pp. (ISBN 0-520-21549-4)
Adrian Kear and Deborah Lynn Steinberg (eds.), Mourning Diana: Nation, Culture and the
Performance of Grief, London: Routledge, 1999, $\mathfrak{1 3 . 9 9}$ paperback, xi+218 pp.
(ISBN 0-415-19393-1)

Tony Walter (ed.), The Mourning for Diana, Oxford: Berg, 1999, £14.99 paperback, xiii+ 286 pp.

(ISBN 1-85973-238-0)

Within the last decade or so there has been a growing recognition among sociologists of the role played by emotions in various aspects of human behaviour (witness, for example, the range of articles appearing in Sociology alone, e.g. Jackson 1993; Craib 1995; Burkitt 1997, and the formation of a BSA study group devoted to the sociology of emotion). This burgeoning focus on emotions has challenged sociology to rethink its dominant conception of the human subject as governed by rational and conscious thought alone. In so doing it has raised a question mark both against the adequacy of the (theoretical) tools used for analysing emotions which have developed from these premises and the ability of sociology in general to provide answers to such questions.

On the basis of this growing interest in emotions one would quite naturally expect a range of sociological responses to the outpouring of grief which seemingly appeared to engulf Britain, and other parts of the world, in the immediate aftermath of the death of Diana, Princess of Wales, on 31 August 1997. This, however, with the exception of two of the books under review, and a very few others, ${ }^{1}$ has not happened. Nevertheless, these two books - albeit from quite different perspectives and from relatively marginalised positions within sociology - are among the first attempts to provide, if not a sociological response in the narrowly conceived sense of the word, then an academic (as opposed to merely journalistic) response to events that then, as now, were widely considered extraordinary by any normal standards. While these two edited collections consider the public mourning for, that is to say, the mourning which flowed from the death of, Diana, Princess of Wales, the other is 
principally an attempt to consider the personal and life-long struggle to mourn the losses encountered in the life of that iconic embodiment of 1960 s counter-culture, John Lennon (hence the mourning of as opposed to for John Lennon). Nevertheless, taken together, all three books can be seen to represent an attempt to take (public) mourning, and its implications for wider culture, seriously.

\section{The limitations of sociology in explaining mourning}

Sociology as traditionally conceived has perceived its primary role as one of explaining the determinate effects of social relationships and of social setting upon specific forms of human behaviour. Since its inception this role has been premised upon an understanding that human behaviour is best viewed as the rational and conscious activity of human beings in contact with others and that this can be understood by humans who are themselves rationally acting agents. Recent attempts to avoid accusations of academic hubris, of valorising the social at the expense, say, of the emotional, have been undertaken partly in earnest of the challenge postmodernism has posed for the production of scientific knowledge, in this case sociology, and because of a growing recognition among sociologists that not everything can be reduced to the social. Ian Craib (1995:152) has earlier chimed a chord with these sentiments of inter-disciplinarity by suggesting that while sociology 'clearly has something to say about emotions', so do biology, psychology, social psychology and various other disciplines.

It is in this regard that Anthony Elliott's The Mourning of John Lennon and the collection edited by Adrian Kear and Deborah Lynn Steinberg, Mourning Diana, have done most to overcome those problems which have tended to beset more 'traditional' aspects of sociology (and in some cases, even those works constituted within the sociology of emotions), by situating their work at the interstices of sociology, social theory, psychoanalysis and cultural studies. By approaching the subject of mourning through this kind of interdisciplinarity and an attempt from the outset to get to grips with mourning as a psycho-social process, the authors of these two books are able carefully to navigate a path which avoids the kind of social reductionism of which the collection of essays edited by Tony Walter, The Mourning for Diana, is guilty.

This difference in approach, between two books which consider the very same episode of public mourning - the death of Diana - is neatly reflected in their titles. Walter's The Mourning for Diana thus approaches events from a more traditional 'sociologistic' perspective, in which mourning is held at a distance as an object of inquiry and regarded as the conscious and outward public display of private emotion. Kear and Steinberg's Mourning Diana, by contrast, uses the theoretical frameworks which underpin it (materialist, post-structuralist, psychoanalytic) to obliterate the public-private, author-object distinction and instead treats mourning 
as a performative action in which the politics of identity and nationhood are intimately configured.

One is encouraged by the blurb accompanying Walter's book and the opportunity it seemingly affords for better understanding 'the depth and breadth of emotion shaking Britain and the world'. It is, however, a failure of the essays contained within Walter's collection to engage substantively with the object of their inquiry, mourning, which leaves the readers expectations unfulfilled. It is, as Ian Burkitt reminds us (1997:37-8), precisely because researchers leave emotion as the object of their inquiry undefined that they leave uncertain exactly what it is that they seek in their research. In this case, because the contributors to Walter's collection leave mourning as the object of their inquiry undefined, the substantive themes addressed appear distinctly off-centre and remain at the level of the social.

Chris Harris, for example, in his contribution to the Walter collection (chapter 7), suggests that the mourning events surrounding Diana's death were in some way a result of media manipulation; that 'the assemblies were the result of media-amplified emotion, not its site and origin' (p. 101). And yet Harris's explanation of events even if we assume that emotions, following Durkheim's notion of a courant sociale, are produced in and through crowd behaviour - leaves us no closer to understanding what emotion actually is or how it is produced. Instead we are left with the impression that the body is a container for the emotions and that the emotions displayed during the mourning for Diana were in some way a presentational add-on or adjunct to personal and private expressions of grief. Harris's account, however, does more to create the impression that people's grief was less heartfelt than it was socially manufactured.

That the mourning for Diana is regarded as a socially constructed event, for which - in the absence of socially proscribed mourning behaviour - people received instruction by watching others, thereby learning to 'feel', is evident throughout the book. Walter, for instance, suggests (p. 23) that those sitting down to write messages in the books of condolence:

did so with no clear idea what to write; they would scan the previous few entries, and write their own variation of that page's emerging theme ... At Buckingham Palace on the first Sunday, one could observe people wandering about wondering what to do. They watched other people - laying flowers, shrieking, quietly contemplating, hugging their partner and thus learnt what was acceptable. This was behaviour that people constructed together, by watching each other, learning from each other: it was genuinely social behaviour.

That the book remains stuck at the level of social explanation is, one feels, partly a consequence of the scope of the book and editorial directive given by Walter that contributors maintain critical detachment from the emotive events about which they were writing; that 'any judgements upon the events that followed Diana's death must arise out of the analysis rather than form the motive for the analysis' (p. 44). 
This book's attempt to move beyond journalistic accounts of the mourning for Diana, to ground events through the use of empirical research and 'solid documentation', is in itself a laudable aim, one with the explicit intention of providing a basis for comparative analysis the next time public mourning on such a scale occurs. I am far from convinced, however, that the best way to approach the public mourning for Diana - a highly charged and emotive moment in British and world history - is through attempting to adopt a non-expressivist, ethically neutral and thereby value-free position.

This position works well enough as a means of documenting events but falls short as a means of explaining the (personal) motivations behind the actions of those who mourned, or else refused to mourn, the passing of Diana. Here Walter (p.37) implies that those people who acted to resist the mourning for Diana did so as rationally acting agents; a resistance which 'can only be answered in terms of the twentieth-century British belief (a belief shared in some, but not all, Western nations) that grief should be personally and privately experienced; for many, to join in the public theatre of grief was simply bad taste.'

Paradoxically, it is in statements like this one where The Mourning for Diana excels in demonstrating the virtues of adopting a 'sociologistic' approach to public mourning whilst at the same time drawing attention to the limits of conventional sociology in explaining how the intra-personal and experiential combine in the process of mourning. By contextualising the mourning for Diana through a comparison with historical, comparative and cross-cultural episodes of mourning, the Walter collection is successfully able to render events explainable. Thus, where sociology works routinely to problematise those areas of social and cultural life which appear so commonplace as to negate academic inquiry (an accusation often levelled at sociology), the Walter book serves to reinscribe the perceived 'uniqueness' of the Diana events within the realm of the familiar through reference to a largely underresearched and, because of this, now largely forgotten folkloric tradition surrounding mourning practices.

This works particularly well as a means of explaining the seemingly strange and thus incomprehensible - the mass floral tributes, condolence cards addressed to the deceased, the transformation of public space into mourning space and creation of shop-window shrines - thereby drawing attention to the limitations of ubiquitous journalistic and cultural commentaries which proved incapable of providing substantive explanation of the Diana events. Thus, one salient feature of the mourning for Diana noted by commentators (and the lay population alike), the expression of grief for a person with whom the majority of mourners had never met, is explained by reference to the accelerated processes of individuation, and the rejection of community-wide rituals of mourning, affecting North European and American society since the latter half of the nineteenth century. By setting the mass public mourning for Diana against the trend towards the increasing privitisation of 
mourning practices within Western societies, Walter's collection goes a considerable way towards explaining how the Diana events were, paradoxically, extraordinary and yet quite normal after all.

That the mourning surrounding Diana's death is approached from a more 'traditional' sociological position, one which excludes the incorporation of embodied or corporeal aspects of lived human experience which have become the focus of many researchers working within the sociology of emotions, is somewhat odd in the light of the advances which sociology has made in recent years. It is this which does more to situate the Walter collection within a growing body of sociological work addressing itself to issues of death, dying and disposal, than to works which constitute the burgeoning field of sociological work on emotion.

\section{The specificity of public mourning}

That which is seemingly overlooked by the Walter collection - the iconic specificity of the referent being mourned - is a theme taken up in Kear and Steinberg's edited collection and in Elliott's The Mourning of John Lennon. Both of these books consider the 'unique' role occupied by the celebrity status of the object being mourned. Elliott thus writes (pp.1,2,3) of Lennon as an ambivalent celebrity at once uncomfortable and yet at home with his celebrity status - in a way which is deeply resonant of the qualities embodied in Diana:

At once idolized and denigrated, Lennon does not fit into the standard categories by which we make sense of celebrities. More than any other cultural icon, ambivalence pervades our memory of him ... Lennon provokes. He is adored, canonized, deified ... Lennon disturbs. He is rebellious, recalcitrant, dangerous.

It is here, at the interface of sociology and cultural studies, that both of these books lead with explorations into the work of identity. Only by unpacking the workings-out of identity do we get a fully textured sense of the working-through embodied in the process of mourning. Thus it is that in psychoanalysis the work of mourning a lost love-object is intimately bound up with the work of (personal) identity; only by exploring the latter can we understand the former. Mourning is in this sense not simply the outward or public display (as a set of social practices) that intimates the experience of private loss but is instead a process which is integral to development of the self. Thus Elliott writes (p.5): 'Without mourning there can be no self-development, understanding, or change. Without mourning we are psychically ill-equipped for creative living. Without mourning we are hampered in preparing for our own loss, as it were, in death'.

A key which unlocks an understanding to the motivational pull behind the mourning, and not mourning, for Diana, Princess of Wales, is a psychoanalytic reading of the range and depth of multiplicatory identifications with which she was 
psychically invested as a love-object. Thus conceived, mourning is understood as a gradual process whereby the ego divests or de-cathects the lost (love) object of 'the intensity of all memories, impulses, and libidinal investments associated with it' (Gorsz 1990:30). Celebrities, in this sense, become the 'blank-screens' upon which our unconscious desires and fantasies are projected. Those losses which cannot be mourned, or are unconsciously denied in our psychic economy, say, the loss of a spouse, may be unleashed by the death of a celebrity with whom we have invested our hopes and fears. Thus, Richard Johnson, in his contribution (chapter 2) to the collection edited by Kear and Steinberg, suggests that for many, including himself, Diana's image was internalised (through a process of introjection) as a 'good' object. Here Johnson explains mourning drawing on a Kleinian 'Object Relations’ approach (p.17):

'Objects' here are the versions of 'real' others we have introjected. In this intensely relational version of psychoanalysis ... we internalize a version of significant others, and this becomes the site of the working out, the splitting off, and at best the reconciliation, of our emotional ambivalences, our loving and our hating. When a loved one dies, we try to recreate and re-embody the lost one, more or less consciously, as an object we can love (again) as a 'good' object. This repeats struggles in our earlier life, especially our struggle to save our internal good objects from our own destructive feelings towards carers in infancy.

It is also in this light that the refusal to acknowledge the mourning for Diana publicly is, according to Johnson (chapter 2) and Adrian Kear (chapter 12), best conceived. Thus it is that by (un)consciously refusing to mourn the death of Diana one was mourning the loss of some other (love) object which one had psychically invested with meaning. That, as Kear (p. 177) puts it, 'the complex identifications through which the things being mourned in "Diana" - including those things being mourned by not mourning her - seemed to matter much more than Diana herself ever could.' In Johnson's essay this mourning through 'not mourning' was amply illustrated by those people on the political right who by 'not mourning' were in some way mourning, say, the attenuation of British reserve and of traditional forms of authority, or for those on the political left, the loss of 'real politics' and the diminution of organised class struggle.

\section{Self and other in the work of mourning}

What is most striking about Elliott's and Kear and Steinberg's books, given that mourning is the primary object of their inquiries, is their conveyance of overlap between self and (the alterity of) the object being mourned, as it routinely occurs in the work of mourning. The idea expressed in the Walter collection, that the researcher should remain detached from the object of her inquiry; that the (authorial) self can be radically divorced from the Other in the study of mourning, is 
rejected, especially in Elliott's book. Here Elliott provides almost a counter critique of empiricism within sociology by deploying his own autobiographical reflections on the loss that Lennon's death represented and through theoretical discussion of the fluidity of (authorial) self as it is expressed in popular biographies of Lennon. It is through this subjectivist approach that Elliott suggests we are best disposed to study mourning, and the experience of loss, not only for an understanding of our general culture but for a richer understanding of our own selves. Elliott thus writes (pp. 6, $11,25)$ :

To the extent that I have concentrated upon the impact of loss upon Lennon's world, I have engaged in the kind of dialogue with my subject that underscores the primacy of emotion, affect and desire ...

I have drawn on my own experience of Lennon - reactions provoked in me by his life and music - throughout this book...

In psychoanalysis, the boundary between self and other is radically fluid. The self may seek to keep inside and outside apart; but at the level of the unconscious one is inserted into the other, and they become all mixed up and tangled.

That the self becomes 'all mixed up and tangled' with the other as an object of inquiry is a point worth recognising not only in relation to popular biography but in scholarly investigation which seeks empirical validation of the 'truth' by denying one's own feelings towards the subject we study. That one's own (un)conscious motivations can be kept outside of that which constitutes empirical 'fact' becomes increasingly difficult to sustain in an emotional space like the one vacated by the death of Diana - a temporal moment which contained the potentiality for both radical social change and at the same time for the recuperation of conservative political values - in which, given the degree of emotional and psychic investment, there was so much at stake.

\section{Conclusion}

That the unconscious can be sufficiently policed as to remain completely detached from what we write about, is, at best, strange - given the role played by identity in the work of mourning - and, at worst, either disingenuous or a form of self-delusion and denial. While there is clearly a requirement on the part of sociology to accurately record episodes of widespread public mourning accurately, there is also a growing demand that we move beyond those more 'static' accounts of emotion in favour of a more dynamic and performative model of mourning; of mourners as emotional bodies in action (Butler 1990). My conclusions here will not please everyone, least of all those with some investment in maintaining the disciplinary boundaries that separate conventional sociology from the domains inhabited by psychoanalysis, social theory and cultural studies. That the Walter book (and books 
like it) calls into question the pursuit of conventional sociology can be seen from its stultifying treatment of mourning. What episodes like the death of Diana, Princess of Wales, call into being is a growing (re)cognition that not all the academic resources for exploring human behaviour lie within sociology itself; that where necessary we go beyond the disciplinary parameters of sociology in search of tools which best serve our needs of social understanding and in so doing help transform and reconstitute the project of sociology.

NOTE

1. See for example, Richards, Wilson and Woodhead (1999) and a number a journals with special issues devoted to the death of Diana, e.g. Journal of Gender Studies 8 (3), 1999.

REFERENCES

Burkitt, I. 1997. 'Social Relationships and Emotions'. Sociology 31: 37-55.

Butler, J. 1990. Gender Trouble: Feminism and the Subversion of Identity. London: Routledge.

Craib, I. 1995. 'Some Comments on the Sociology of Emotions'. Sociology 29:151-8.

Gorsz, E. 1990. Jacques Lacan: A Feminist Introduction. London: Routledge.

Jackson, S. 1993. 'Even Sociologists Fall in Love: An Exploration in the Sociology of Emotions'. Sociology 27: 201-20.

Richards, J., Wilson, S. and Woodhead. 1999. Diana, the Making of a Media Saint. London: I. B. Tauris.

Biographical note: MICHAEL BRENNAN is a doctoral research student in the Department of Sociology at the University of Warwick. His research considers the public mourning for Diana, Princess of Wales, alongside that of the mourning which followed the Hillsborough football stadium disaster.

Address: Department of Sociology, University of Warwick, Coventry, CV47AL. 